\title{
Plasma levels of pentraxin-3, an inflammatory protein involved in fertility, are reduced in women with polycystic ovary syndrome
}

\author{
Flavia Tosi ${ }^{1}$, Daniela Di Sarra', Cecilia Bonin ${ }^{2}$, Francesca Zambotti ${ }^{1}$, \\ Marlene Dall'Alda ${ }^{1}$, Tom Fiers ${ }^{3}$, Jean-Marc Kaufman ${ }^{3,4}$, Matilde Donati ${ }^{1}$, \\ Massimo Franchi ${ }^{2}$, Maria Elisabetta Zanolin ${ }^{5}$, Enzo Bonora ${ }^{1}$ and Paolo Moghetti ${ }^{1}$ \\ ${ }^{1}$ Section of Endocrinology, Diabetes and Metabolism, Department of Medicine and ${ }^{2}$ Obstetrics and Gynecology, \\ University of Verona and Azienda Ospedaliera Universitaria Integrata Verona, P.le Stefani, I-37126 Verona, Italy, \\ ${ }^{3}$ Laboratory for Hormonology and ${ }^{4}$ Department of Endocrinology, Ghent University Hospital, B-9000 Ghent, \\ Belgium and ${ }^{5}$ Department of Public Health and Community Medicine, University of Verona, I-37131 Verona, Italy
}

\author{
Correspondence \\ should be addressed \\ to P Moghetti \\ Email \\ paolo.moghetti@univr.it
}

\begin{abstract}
Objective: Pentraxin-3 (PTX3), like C-reactive protein (CRP), is an acute-phase protein that belongs to the pentraxin superfamily. Moreover, it is expressed in the cumulus oophorus and appears to be involved in female fertility. The aim of the present study was to assess whether PTX3 levels are altered in polycystic ovary syndrome (PCOS) women and whether they show any relationship with the main features of these subjects.

Design: A cross-sectional study was conducted at the outpatient clinic of an academic centre.

Methods: A total of 66 women affected with PCOS and 51 healthy controls were studied. Plasma PTX3 and serum CRP were measured by ELISA. Androgens were measured by liquid chromatography-mass spectrometry and free testosterone was measured by equilibrium dialysis. In PCOS women, insulin sensitivity was assessed by the glucose clamp technique. Results: Adjusting for age and BMI, plasma PTX3 was reduced in PCOS women $(P=0.036)$, in contrast with serum CRP, which was increased $(P=0.004)$. In multiple regression analysis, serum androgens and other endocrine and ovarian features of PCOS were predictors of PTX3 levels, whereas body fat was the main independent predictor of CRP concentrations. Conclusions: Plasma PTX3 levels were reduced in PCOS women and independently associated with hyperandrogenism and other endocrine and ovarian features of PCOS.
\end{abstract}

\section{Introduction}

Polycystic ovary syndrome (PCOS) is a complex disorder characterised by hyperandrogenism and ovarian dysfunction. Metabolic alterations, such as obesity, insulin resistance, abnormal glucose tolerance and lipid abnormalities, are also common findings in this condition, suggesting that PCOS women might have an increased cardiovascular risk later in life (1). In this regard, a number of surrogate markers of cardiovascular risk support this hypothesis, although definite proof is still lacking $(2,3)$.

C-reactive protein (CRP) is an acute-phase protein. It belongs to the pentraxin superfamily and is one of the best characterised biomarkers of low-grade chronic inflammation, a key process in the pathogenesis of atherosclerosis (4). Several epidemiological studies, both in subjects with increased cardiovascular risk and in the general population, have shown that serum CRP independently predicts cardiovascular events (5). Interestingly, CRP levels were increased in PCOS women (6).

Pentraxin-3 (PTX3) is another protein that belongs to the pentraxin superfamily, which has a fundamental role in innate and adaptive immune response (7). As found for serum CRP, PTX3 levels predicted cardiovascular events
(C) 2014 European Society of Endocrinology Printed in Great Britain
Published by Bioscientifica Ltd. 
independently of traditional risk factors $(8,9,10)$. Interestingly, these findings were not affected by inclusion of serum CRP in the analysis, suggesting PTX3 levels carry supplemental information.

PTX3 is primarily synthesised by leukocytes, dendritic cells, monocytes and macrophages in response to microbial components or pro-inflammatory cytokines (11). In addition, other cell types, such as endothelial cells, fibroblasts, smooth muscle cells and adipocytes, can produce PTX3 in response to appropriate stimulation, supporting the involvement of this protein not only in inflammation but also in angiogenesis and matrix deposition $(11,12)$. Furthermore, PTX3 is synthesised in the cumulus oophorus under hormonal stimuli and plays an important role in assembling the extracellular matrix of the cumulus during the preovulatory period, guaranteeing normal oocyte development and fertilisation $(13,14)$.

As a whole, these findings make PTX3 a very interesting biomarker in PCOS women, who are characterised by both infertility and cardiometabolic risk. However, information concerning PTX3 concentrations in this population is very limited (15).

The aims of this study were to assess whether plasma PTX3 levels are altered in PCOS women and to analyse the relationships between this protein, serum CRP and the main anthropometric, metabolic and hormonal features of these patients.

\section{Subjects and methods}

\section{Subjects}

A total of 70 women with PCOS, diagnosed according to the Rotterdam criteria (16), were studied. These subjects were recruited consecutively among those referring to the outpatient clinic of the Division of Endocrinology, Diabetes and Metabolism of the Verona City Hospital for hirsutism and/or oligoamenorrhoea and who were included in the Verona PCOS Pathophysiology and Phenotype (Verona 3P) Study (17), a project aimed at building a comprehensive database for investigating the relationships between the different features of these women. These patients were part of the cohort investigated to assess the relationships between PCOS phenotypes and insulin sensitivity (17). In these women, hyperandrogenism was defined by the presence of hirsutism and/or increased serum free testosterone, in accordance with the AE-PCOS Society guidelines for diagnosis of PCOS (18). Secondary causes of PCOS were ruled out by systematic thyroid-stimulating hormone (TSH), prolactin and 17-hydroxyprogesterone assays. To exclude non-classical adrenal hyperplasia, the adrenocorticotrophic hormone-stimulation test was carried out when baseline 17-hydroxyprogesterone was $>5 \mathrm{nmol} / \mathrm{l}$. When indicated on clinical grounds, the overnight dexamethasone suppression test was carried out to exclude hypercortisolism and imaging investigations were carried out to exclude androgen-secreting tumours.

All subjects were studied in the early follicular phase of the menstrual cycle, or after at least 3 months of amenorrhoea. None of these patients were suffering from any other disease, including renal dysfunction, rheumatic and other autoimmune diseases or recent infections. A few women with TSH levels close to the upper limit of the reference range (3.0-4.2 mU/1) were submitted to thyroid peroxidase antibody assay and thyroid ultrasonography, which were negative in all of them. In addition, they should not have received metformin, oral contraceptives, antiandrogens or any other medications potentially interfering with measurements carried out in the study including statins, acetylsalicylic acid (ASA) or glucocorticoids - in the previous 6 months. Four of these subjects were subsequently excluded as they reported recent use of non-steroidal anti-inflammatory drugs (NSAIDs). Therefore, 66 PCOS women were included in the analyses.

A total of 51 healthy, non-hirsute women, with regular ovulatory cycles, normal ovarian morphology and normal weight served as controls. These women were recruited through advertisements at the local university, nursing school and at Verona City Hospital. All subjects gave their written informed consent to the study, which was conducted in accordance with the Declaration of Helsinki and approved by our Institutional Ethics Committee.

\section{Protocol}

All subjects underwent a complete physical examination, including measurement of height, weight, waist circumference, systolic and diastolic blood pressure and hirsutism score (19). Blood samples for PTX3 and CRP assays and for measurement of endocrine and metabolic parameters were collected at $\sim 0800 \mathrm{~h}$, after overnight fasting.

The endocrine profile comprised assessment of gonadotrophins, total and free testosterone, androstenedione and SHBG. The metabolic profile comprised measurement of serum lipids (total, HDL-cholesterol and triglycerides) and uric acid, as well as of plasma glucose and insulin at baseline and thereafter every $30 \mathrm{~min}$ for $2 \mathrm{~h}$ during a $75 \mathrm{~g}$ oral glucose tolerance test. 
In all subjects, insulin sensitivity was estimated by the HOMA-index (20). Moreover, in PCOS women it was also measured by the hyperinsulineamic euglyceamic clamp technique (21), according to the Verona 3P Study protocol. The clamp studies were carried out as described previously (22), with an insulin infusion rate of $80 \mathrm{mU} / \mathrm{m}^{2} \times \mathrm{min}$. Insulin-stimulated glucose utilisation (M-clamp value) was expressed per fat-free mass (FFM), as assessed by bioelectrical impedance analysis (23). Ultrasound examination of the ovaries was carried out using a three-dimensional device (Voluson 730 Pro, General Electrics, Hatfield, UK), whenever possible by a trans-vaginal approach.

\section{Assays}

Plasma PTX3 and serum CRP were assayed by ELISA methods (Quantikine Kit, R\&D Systems, Inc., Minneapolis, MN, USA; and ultrasensitive ELISA Kit, Diagnostic Biochem Canada, Inc., Dorchester, ON, Canada respectively). The intra- and inter-assay coefficients of variation $(\mathrm{CV})$ were below $6 \%$ for both methods.

Serum total testosterone and androstenedione were measured by liquid chromatography-mass spectrometry using a Micromass Quattro Premier XE Mass Spectrometer from Waters Corporation (Milford, MA, USA). For testosterone, the limit of quantification was $2.5 \mathrm{ng} / \mathrm{ml}$, the intra-assay CV $9.1 \%$ at concentration $14 \mathrm{ng} / \mathrm{dl}$ and the inter-assay CV $9.3 \%$ at concentration $26 \mathrm{ng} / \mathrm{dl}$; for androstenedione, the limit of quantification was $1 \mathrm{ng} / \mathrm{dl}$, the intra-assay $\mathrm{CV} 3 \%$ at $64 \mathrm{ng} / \mathrm{dl}$ and the inter-assay CV $4.6 \%$ at concentration $58 \mathrm{ng} / \mathrm{dl}$. Free testosterone fraction was estimated by equilibrium dialysis (24), inter-assay $\mathrm{CV}<8 \%$.

Serum SHBG and insulin were assayed by immunoradiometric methods (Orion Diagnostica, Espoo, Finland; and Biosource, Fleurus, Belgium respectively). Automated chemiluminescence methods were used to measure gonadotrophins (ADVIA Centaur XP, Siemens, Milan, Italy). Plasma glucose was assayed immediately after withdraw using a glucose analyser (YSI 2300 STAT PLUS, Yellow Springs, OH, USA). Enzymatic methods were used to measure serum lipids and uric acid, by an automated analyser (Dimension Vista 1500, Siemens).

\section{Calculations and statistical analysis}

LDL-cholesterol was calculated by the Friedewald formula (25). The insulin resistance HOMA-index was calculated by using the following formula: fasting plasma glucose $(\mathrm{mmol} / \mathrm{l}) \times$ fasting serum insulin $(\mathrm{mU} / \mathrm{l}) / 22.5$ (19). Ovarian volume was measured by the ellipsoidal formula: $\pi / 6 \times(\mathrm{D} 1 \times \mathrm{D} 2 \times \mathrm{D} 3)$, where $\mathrm{D} 1, \mathrm{D} 2$ and $\mathrm{D} 3$ are the three diameters of the ovary.

Continuous variables were described by median and interquartile range, as most of them were not normally distributed. Normality of the distribution of the studied variables was assessed by the Shapiro-Wilk test and not normally distributed variables were $\log$ or square root transformed before analysis. Comparisons between groups were carried out using the Student's $t$-test for unpaired data. As BMI, triglycerides and the ovarian follicle count could not be normalised, comparisons of these variables were carried out by non-parametric Mann-Whitney $U$ test. Because PCOS women and healthy controls had different BMI and age, PTX3 and CRP data in these groups were adjusted for differences in these variables by ANCOVA.

Pearson or Spearman correlation coefficients, as appropriate, were calculated to assess the relationships between either PTX3 or CRP levels and other relevant variables. Subsequently, multiple regression analyses were carried out, using PTX3 or CRP as the dependent continuous variable, and adiposity, insulin sensitivity and endocrine or ovarian parameters (free testosterone, total testosterone, androstenedione, LH:FSH ratio or number of ovarian follicles), in different models, as independent variables. In these analyses, independent variables were chosen on the basis of associations in univariate analyses with the dependent variables and/or of biological plausibility.

For power calculation, we hypothesised that PTX3 and CRP levels could have similar behaviours in PCOS women. On the basis of our previous results of serum CRP in PCOS women (22), a group size of 50 each allows us to detect a difference of $0.7 \mathrm{mg} / \mathrm{l}$ in CRP between controls $($ mean $=2.8 \mathrm{mg} / \mathrm{l}$, s.D. $=0.8)$ and PCOS women (s.D. $=2.0)$ with a $80 \%$ power and $5 \%$ alpha error, considering the use of the Mann-Whitney $U$ test. $P$ values $<0.05$ were considered statistically significant. Analyses were carried out using STATA version 12.1 (StataCorp., College Station, TX, USA).

\section{Results}

Among the 66 PCOS women, 58 had hyperandrogenism, 59 oligoanovulation and 58 polycystic ovary (PCO) morphology. According to the individual combination of these features, 51 PCOS subjects had the 'classic' phenotype (hyperandrogenism and oligoanovulation, with or without PCO morphology), seven the 'ovulatory' phenotype (hyperandrogenism and PCO morphology) and eight the 'normoandrogenic' phenotype 
Table 1 Main characteristics of PCOS women and of healthy controls ${ }^{a}$.

\begin{tabular}{|c|c|c|c|}
\hline & PCOS $n=66$ & Controls $n=51$ & $\boldsymbol{P}$ \\
\hline Pentraxin-3 (ng/ml) & $0.84(0.46-1.62)$ & $1.15(0.76-1.88)$ & 0.036 \\
\hline C-reactive protein $(\mathrm{mg} / \mathrm{l})^{\mathrm{b}}$ & $0.78(0.31-2.33)$ & $0.52(0.20-0.87)$ & 0.004 \\
\hline Age (years) & $23.0(19.0-27.0)$ & $27.5(24.0-32.0)$ & 0.001 \\
\hline BMI $\left(\mathrm{kg} / \mathrm{m}^{2}\right)$ & $28.5(22.9-33.9)$ & $21.0(19.7-22.5)$ & $<0.001$ \\
\hline Waist circumference $(\mathrm{cm})$ & $95.0(76.7-105.2)$ & $74.0(71.2-77.0)$ & $<0.001$ \\
\hline Fat mass $(\mathrm{kg})^{\mathrm{c}}$ & $25.6(19.2-37.9)$ & & \\
\hline Fat-free mass (FFM) $(\mathrm{kg})^{\mathrm{c}}$ & $49.8(43.2-56.2)$ & & \\
\hline Ferriman-Gallwey score ${ }^{c}$ & $9.0(4.0-15.0)$ & & \\
\hline Systolic blood pressure $(\mathrm{mmHg})$ & $120(110-130)$ & $118(110-120)$ & 0.127 \\
\hline Diastolic blood pressure $(\mathrm{mmHg})$ & $80(70-89)$ & $75(70-80)$ & 0.194 \\
\hline Fasting plasma glucose (mg/dl) & $86.0(79.0-94.0)$ & $81.0(73.8-86.4)$ & 0.001 \\
\hline Fasting serum insulin (mU/l) & $14.8(8.7-23.1)$ & $6.6(4.4-9.3)$ & $<0.001$ \\
\hline HOMA-IR & $2.96(1.81-5.29)$ & $1.32(0.83-1.71)$ & $<0.001$ \\
\hline M-clamp $(\mathrm{mg} \times \mathrm{kg} F F M \times \min )^{\mathrm{c}, \mathrm{d}}$ & $9.72(6.71-11.94)$ & & \\
\hline Total cholesterol (mg/dl) & $162(149-188)$ & $161(146-188)$ & 0.969 \\
\hline HDL-cholesterol (mg/dl) & $49.5(41.5-56.5)$ & $54.8(47.5-64.2)$ & 0.009 \\
\hline LDL-cholesterol (mg/dl) & $98.3(82.0-116.5)$ & $87.2(79.1-108.7)$ & 0.623 \\
\hline Triglycerides (mg/dl) & $63.0(49.0-95.0)$ & $56.5(41.3-70.6)$ & 0.011 \\
\hline Uric acid (mg/dl) & $4.2(3.7-5.2)$ & $3.7(3.4-4.0)$ & 0.002 \\
\hline SHBG (nmol/l) & $31.5(21.0-44.7)$ & $64.9(53.2-88.3)$ & $<0.001$ \\
\hline LH/FSH & $1.57(0.95-2.33)$ & $0.69(0.44-1.12)$ & $<0.001$ \\
\hline Total testosterone (ng/dl) & $36.9(24.9-47.4)$ & $25.9(20.9-32.4)$ & $<0.001$ \\
\hline Free testosterone (ng/dl) & $0.60(0.49-0.89)$ & $0.28(0.25-0.39)$ & $<0.001$ \\
\hline$\Delta 4$-Androstenedione (ng/dl) & $154.2(123.3-216.2)$ & $123.3(110.0-155.9)$ & 0.004 \\
\hline Ovarian follicles $(n)$ & $14.0(12.0-16.0)$ & $4.0(3.0-4.0)$ & $<0.001$ \\
\hline Ovarian volume (ml) & $11.5(8.1-13.8)$ & $7.6(5.4-8.9)$ & $<0.001$ \\
\hline
\end{tabular}

(oligoanovulation and PCO morphology). Table 1 shows the main characteristics of these subjects, as compared with healthy controls. The two groups differed in terms of several anthropometric, metabolic and endocrine parameters: in particular, PCOS women had higher BMI, waist circumference, plasma glucose, serum insulin, HOMA-IR, triglycerides, uric acid, androgens and LH:FSH ratio. Conversely, they had lower HDL-cholesterol and SHBG levels. As expected, the US ovarian parameters were also significantly different between groups. Age was slightly higher in controls, although this difference was of unlikely biological significance. Six of these patients had an impaired glucose tolerance.

The M-clamp value was below the lower limit of our reference interval $(11.75 \mathrm{mg} / \mathrm{kg} \mathrm{FFM} \times \mathrm{min})$ in 47 out of 66 PCOS subjects, showing that $71.2 \%$ of them were insulin resistant.

Figure 1 shows PTX3 and CRP levels in the two groups of subjects. Adjusting for age and BMI, plasma PTX3 was significantly lower in PCOS patients than in controls $(P=0.036)$. Conversely, serum CRP was higher in PCOS patients than in controls $(P=0.004)$.
No relationship was observed between PTX3 and CRP levels $(r=-0.122, P=0.196)$. Table 2 shows the univariate relationships between either PTX3 or CRP levels and several anthropometric, endocrine and metabolic parameters. Interestingly, distinct relationships were observed between these two inflammatory proteins that belong to the pentraxin superfamily and several features of these women.
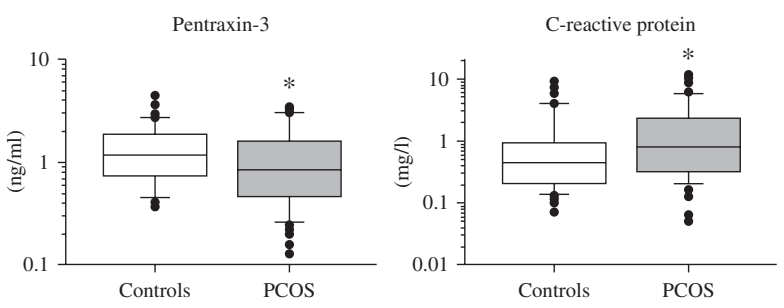

\section{Figure 1}

Box plots of plasma pentraxin-3 (left panel) and serum C-reactive protein (right panel) in PCOS women (grey box) as compared with healthy controls (white box). ${ }^{\star} P<0.05$. 
Table 2 Univariate relationships between plasma PTX3 or serum CRP levels and clinical, metabolic and endocrine parameters in the whole population.

\begin{tabular}{|c|c|c|c|c|}
\hline & \multicolumn{2}{|c|}{ PTX3 } & \multicolumn{2}{|c|}{ CRP } \\
\hline & $r$ & $P$ & $r$ & $P$ \\
\hline Age & 0.049 & 0.603 & -0.065 & 0.496 \\
\hline $\mathrm{BMI}$ & -0.189 & 0.043 & 0.550 & $<0.001$ \\
\hline Waist circumference & -0.155 & 0.216 & 0.729 & $<0.001$ \\
\hline Fat mass ${ }^{a}$ & -0.119 & 0.345 & 0.740 & $<0.001$ \\
\hline Fat-free mass ${ }^{a}$ & -0.152 & 0.226 & 0.684 & $<0.001$ \\
\hline Ferriman-Gallwey score ${ }^{a}$ & 0.077 & 0.546 & 0.059 & 0.639 \\
\hline Systolic blood pressure & -0.108 & 0.327 & 0.322 & 0.002 \\
\hline Diastolic blood pressure & -0.208 & 0.056 & 0.324 & 0.002 \\
\hline Fasting plasma glucose & -0.147 & 0.116 & 0.252 & 0.007 \\
\hline Fasting insulin & -0.210 & 0.024 & 0.402 & $<0.001$ \\
\hline HOMA-IR & -0.215 & 0.021 & 0.403 & $<0.001$ \\
\hline M-clamp ${ }^{a, b}$ & -0.001 & 0.995 & -0.398 & 0.001 \\
\hline Total cholesterol & 0.026 & 0.785 & 0.010 & 0.920 \\
\hline HDL-cholesterol & 0.230 & 0.018 & -0.311 & 0.002 \\
\hline LDL-cholesterol & -0.166 & 0.090 & 0.083 & 0.409 \\
\hline Triglycerides & -0.174 & 0.062 & 0.233 & 0.014 \\
\hline Uric acid & 0.020 & 0.857 & 0.513 & $<0.001$ \\
\hline SHBG & 0.126 & 0.184 & -0.352 & 0.001 \\
\hline LH/FSH & -0.343 & 0.006 & -0.071 & 0.578 \\
\hline Total testosterone $(\mathrm{ng} / \mathrm{dl})$ & -0.287 & 0.002 & 0.188 & 0.051 \\
\hline Free testosterone & -0.329 & 0.001 & 0.352 & 0.001 \\
\hline$\Delta 4$-Androstenedione & -0.344 & 0.001 & 0.105 & 0.295 \\
\hline Ovarian follicles & -0.286 & 0.006 & 0.117 & 0.265 \\
\hline Ovarian volume & -0.181 & 0.083 & -0.062 & 0.563 \\
\hline
\end{tabular}

In the whole sample of PCOS women and controls, plasma PTX3 was associated inversely with serum total and free testosterone, androstenedione and LH:FSH ratio, as well as with the number of ovarian follicles. Similar findings were found when PCOS women were analysed separately (data not shown). However, no relationships were observed between PTX3 and either the indices of adiposity or the metabolic variables, except for weak relationships with BMI, serum insulin and the HOMAindex (inverse) and HDL-cholesterol (direct). These latter associations were not maintained when the analyses were carried out in PCOS patients only (data not shown).

Conversely, CRP levels correlated directly with a number of anthropometric (BMI, fat and FFM and waist circumference), metabolic (fasting plasma glucose and serum insulin, HOMA-IR, triglycerides, uric acid and blood pressure) and endocrine (free testosterone) features. Moreover, serum CRP correlated inversely with M-clamp value, serum HDL-cholesterol and SHBG. Similar relationships were observed when the analysis was carried out in PCOS women only (data not shown).

To assess the role of anthropometric, metabolic and endocrine features in the abnormalities of PTX3 and CRP levels, different models of multiple regression analysis were subsequently carried out. Plasma PTX3 was inversely associated with either serum androgens, LH:FSH ratio or number of ovarian follicles, but not with body mass and insulin sensitivity (Table 3). However, serum CRP was directly associated with BMI (or fat mass, data not shown), but not with endocrine features or ovarian follicle number (Table 3).

\section{Discussion}

In this study, we have measured the circulating levels of PTX3 and CRP, two acute-phase proteins, in PCOS women and healthy controls. We have found that PTX3 concentrations were lower, whereas CRP levels were higher in PCOS women than in controls. Another prominent difference in these proteins' behaviours was that plasma PTX3 was associated inversely with the endocrine and ovarian features typical of PCOS, whereas it did show weak associations, if any, with the anthropometric and metabolic features; conversely CRP levels were associated with several anthropometric, metabolic and endocrine features of these women. 
Table 3 Predictive variables of PTX3 and CRP concentrations in the multivariate regression analyses ${ }^{a}$.

\begin{tabular}{|c|c|c|c|c|}
\hline \multirow[b]{2}{*}{$\begin{array}{l}\text { Independent } \\
\text { variables }\end{array}$} & \multicolumn{2}{|c|}{ PTX3 } & \multicolumn{2}{|l|}{ CRP } \\
\hline & $\begin{array}{c}\text { Standardised } \\
\beta \text {-coefficient }\end{array}$ & $P$ & $\begin{array}{l}\text { Standardised } \\
\beta \text {-coefficient }\end{array}$ & $P$ \\
\hline & $R^{2} 0.110$ & & $R^{2} 0.357$ & \\
\hline BMI & 0.040 & 0.771 & 0.617 & $<0.001$ \\
\hline HOMA-IR & -0.090 & 0.456 & 0.027 & 0.802 \\
\hline Free testosterone & $\begin{array}{r}-0.304 \\
R^{2} 0.156\end{array}$ & 0.014 & $\begin{array}{r}-0.059 \\
R^{2} 0.379\end{array}$ & 0.571 \\
\hline BMI & -0.119 & 0.312 & 0.624 & $<0.001$ \\
\hline HOMA-IR & -0.077 & 0.503 & 0.013 & 0.895 \\
\hline Total testosterone & $\begin{array}{r}-0.301 \\
R^{2} 0.154\end{array}$ & 0.002 & $\begin{array}{r}-0.064 \\
R^{2} 0.364\end{array}$ & 0.430 \\
\hline BMI & -0.041 & 0.736 & 0.582 & $<0.001$ \\
\hline HOMA-IR & -0.143 & 0.238 & 0.034 & 0.754 \\
\hline Androstenedione & $\begin{array}{r}-0.327 \\
R^{2} 0.246\end{array}$ & $<0.001$ & $\begin{array}{r}-0.009 \\
R^{2} 0.568\end{array}$ & 0.915 \\
\hline BMI & -0.250 & 0.076 & 0.701 & $<0.001$ \\
\hline HOMA-IR & -0.141 & 0.314 & 0.094 & 0.386 \\
\hline LH/FSH & $\begin{array}{r}-0.437 \\
R^{2} 0.155\end{array}$ & 0.001 & $\begin{array}{r}0.041 \\
R^{2} 0.415\end{array}$ & 0.637 \\
\hline BMI & -0.182 & 0.156 & 0.651 & $<0.001$ \\
\hline HOMA-IR & -0.087 & 0.485 & 0.020 & 0.852 \\
\hline Follicle number & -0.240 & 0.021 & -0.104 & 0.222 \\
\hline
\end{tabular}

${ }^{a} R^{2}$ is reported for each model; statistically significant $P$ values are in bold.

In multivariate analyses, plasma PTX3 was predicted by the endocrine features, and serum CRP by adiposity.

The striking differences in the behaviours of these two proteins appear somewhat surprising. In actual fact, both of them are acute-phase proteins belonging to the pentraxin superfamily (7) and they were both shown to be the independent predictors of cardiovascular risk in prospective studies $(5,8,9,10)$, suggesting similar properties. Nonetheless, it is known that these two proteins differ in terms of several physiological aspects. While CRP is primarily synthesised in the liver (4), PTX3 is produced by a number of different cells: leukocytes, macrophages, dendritic and myeloid cells, mesangial, epithelial and endothelial cells, adipocytes and ovarian granulosa cells (11), and it was hypothesised that the multiple sources of PTX3 may serve different functions according to the tissue or the cellular component from where it is produced. Moreover, PTX3 production is stimulated by several proinflammatory cytokines, such as IL1 $\beta, \mathrm{TNF} \alpha$ and IL10, and by TLR-agonists and oxidised LDL, but not by IL6 (26). Conversely, the latter is the most potent activator of CRP secretion (4). In addition, in several studies carried out in different conditions, the correlation between PTX3 and CRP levels was weak or even absent $(9,27,28)$. It is noteworthy that, in prospective studies, PTX3 was a predictor of cardiovascular events and mortality, independent of serum CRP $(8,9,10)$. As a whole these data suggest that, besides some shared pathophysiological properties, these two proteins may have different biological meanings.

To the best of our knowledge, only one recent study, carried out by Aydogdu et al. (15), previously assessed PTX3 levels in PCOS women. Unlike in our findings, in this study PTX3 concentrations were slightly higher in PCOS subjects and correlated directly with HOMA-index and serum CRP, and inversely with HDL-cholesterol. Unfortunately, these authors did not assess the relationships between PTX3 and androgen levels. The discrepancies between our results and these data are not easily explained. In Aydogdu's study mean BMI of PCOS women was in the normal range, whereas in our study it was higher. Although we did not find any relationship between adiposity and PTX3 levels, it should be taken into account that obesity is associated with hyperandrogenism (29). As a consequence, we could hypothesise that PCOS women recruited in the two studies differed in terms of disease severity. Moreover, insulin sensitivity and serum androgens were measured by different methods in the two studies (euglycaemic glucose clamp vs HOMA-index and liquid chromatography-mass spectrometry vs routine assays respectively).

An intriguing, novel finding of our study is the inverse relationship between PTX3 and serum androgens. Consistent with our findings, in a recent study comparing the metabolic effects of different administration routes of combined contraceptives, PTX3 levels increased after either oral or transdermal contraceptive administration, concurrently with free androgen index reduction (30). In this regard, although no data are available on the effect of androgens on PTX3 production, several studies have shown that androgens possess immune-modulating properties and, in particular, can suppress the activity of pro-inflammatory cytokines, while enhancing the activity of anti-inflammatory factors $(31,32,33)$. Moreover, it is noteworthy that PTX3 levels are significantly lower in men than in women (34), supporting our hypothesis of a negative regulation by androgens.

The anti-inflammatory properties of androgens suggested that these hormones may play a protective role in the limitation of vascular inflammation underpinning the pathophysiology of atherosclerosis (32). It was speculated that this protective effect could explain why until now no studies have demonstrated an increase in cardiovascular events in hyperandrogenic PCOS women (35), despite them having frequent metabolic alterations and abnormalities in surrogate markers of cardiovascular risk $(1,2,3)$. 
Consistently, in vitro studies showed that androgens, in high physiological doses, inhibit atheroma formation $(36,37)$. Moreover, previous studies reported that serum androstenedione and testosterone were inversely associated with intima-media thickness in pre- and postmenopausal women $(38,39)$. We can thus hypothesise that, in women with PCOS, the adverse metabolic alterations associated with hyperandrogenism and fat mass excess may be counterbalanced by favourable effects of androgens on inflammatory molecules, such as PTX3. Nonetheless, we must be aware that finding an association does not necessarily mean that there is a cause-effect relationship. Moreover, the potential adverse role of PTX3 on cardiovascular risk also remains speculative, as it was hypothesised that increase in the level of this protein in subjects with cardiovascular events could be an adaptive and even a protective phenomenon, limiting tissue damage associated with complement overactivation (40).

The CRP behaviour seems to be an exception to the hypothesis of anti-inflammatory properties of androgens; in our study serum CRP and testosterone levels showed a positive association in univariate regression and no relationship in multiple regression analysis. Nonetheless, in a larger sample of lean hyperandrogenic women, we have previously found that, although serum CRP was directly associated with serum free testosterone in univariate analysis, the relationship disclosed an opposite direction when the data were adjusted for fat mass and insulin sensitivity (22). These findings suggest that the apparent direct association between CRP and androgen levels might be mediated by the association between androgens and fat mass (29) on one hand, and the strong IL6 mediated relationship between fat mass and serum CRP (41) on the other.

Besides any putative protective cardiovascular effect, an androgen-induced reduction in PTX3 secretion could have detrimental effects on the reproductive aspects of PCOS women, as PTX3 is necessary for cumulus cell-oocyte integrity in the periovulatory period. In actual fact, this protein plays an essential role in the stabilisation of the extracellular matrix of the cumulus oophorus and the protection from its proteolytic degradation (11). Consistently, the homozygous null-PTX3 mice are subfertile, probably because of the disruption of the structural integrity of the cumulus complex (42). Interestingly, Ptx 3 expression in the granulosa cells is regulated by growth differentiation factor 9 (GDF9), which is down-regulated by testosterone via its own receptor, resulting in early follicular arrest (43). These findings may thus suggest a role for this pathway in the ovarian abnormalities typical of PCOS. Consistently, some recent studies have reported that GDF9 mRNA expression in oocyte and cumulus granulosa cells is abnormally reduced in PCOS women $(44,45)$.

The main strengths of our study are the comprehensive assessment of clinical, endocrine and metabolic characteristics of PCOS women, and use of state-of-the-art methodology for the measurement of several parameters, such as androgen levels and insulin sensitivity, which are important in the interpretation of results.

We also acknowledge some limitations in our study. The first limitation is intrinsic to the multiple differences between PCOS and control women. To overcome this problem, we carried out the multivariable analysis in order to assess the independent roles of age and anthropometric, metabolic and endocrine features in the abnormalities of these proteins' levels. In general, there were small changes in mean differences when these features were added as covariates to our models. However, we cannot exclude that there may be residual confounding by these factors. Secondly, our sample was entirely constituted of Caucasian women. Therefore, extrapolation of our results to other ethnic groups should be undertaken with caution. Finally, as our cohort of PCOS patients mostly consisted of women with the 'classic' phenotype, our findings should also be extrapolated with caution to women with different PCOS phenotypes. Further research, examining a larger number of women belonging to different ethnic groups and to all different PCOS phenotypes, is needed to clarify these issues.

In conclusion, blood concentrations of PTX3 and CRP, two acute-phase proteins that belong to the pentraxin superfamily, show strikingly different behaviours in PCOS women. We hypothesise that this phenomenon could be due to differences in the regulatory mechanisms of these proteins. In particular, PTX3 secretion seems to be negatively affected by androgen excess, whereas CRP levels are mainly and positively influenced by fat excess. Further research is needed to assess the intriguing, potential implications of PTX3 alterations in PCOS women, in terms of both adverse effects on reproduction and protection from cardiovascular risk.

\section{Declaration of interest}

The authors declare that there is no conflict of interest that could be perceived as prejudicing the impartiality of the research reported.

\section{Funding}

This study was supported by academic grants to P Moghetti from the University of Verona. 


\section{References}

1 Wild RA, Carmina E, Diamanti-Kandarakis E, Dokras A, Escobar-Morreale HF, Futterweit W, Lobo R, Norman RJ, Talbott E \& Dumesic DA. Assessment of cardiovascular risk and prevention of cardiovascular disease in women with the polycystic ovary syndrome: a consensus statement by the Androgen Excess and Polycystic Ovary Syndrome (AE-PCOS) Society. Journal of Clinical Endocrinology and Metabolism 201095 2038-2049. (doi:10.1210/jc.2009-2724)

2 Diamanti-Kandarakis E, Paterakis T \& Kandarakis HA. Indices of lowgrade inflammation in polycystic ovary syndrome. Annals of the New York Academy of Sciences 20061092 175-186. (doi:10.1196/annals.1365.015)

3 Randeva HS, Tan BK, Weickert MO, Lois K, Nestler JE, Sattar N \& Lehnert H. Cardiometabolic aspects of the polycystic ovary syndrome. Endocrine Reviews 201233 812-841. (doi:10.1210/er.2012-1003)

4 Pepys MB \& Hirschfield GM. C-reactive protein: a critical update. Journal of Clinical Investigation 2003111 1805-1812. (doi:10.1172/ JCI18921)

5 Buckley DI, Fu R, Freeman M, Rogers K \& Helfand M. C-reactive protein as a risk factor for coronary heart disease: a systematic review and meta-analyses for the U.S. Preventive Services Task Force. Annals of Internal Medicine 2009 151 483-495. (doi:10.7326/0003-4819-151-7200910060-00009)

6 Escobar-Morreale HF, Luque-Ramírez M \& González F. Circulating inflammatory markers in polycystic ovary syndrome: a systematic review and metaanalysis. Fertility and Sterility 201195 1048-1058. (doi:10.1016/j.fertnstert.2010.11.036)

7 Mantovani A, Garlanda C, Doni A \& Bottazzi B. Pentraxins in innate immunity: from C-reactive protein to the long pentraxin PTX3. Journal of Clinical Immunology 200828 1-13. (doi:10.1007/s10875-007-9126-7)

8 Jenny NS, Arnold A, Kuller L, Russell T \& Psaty B. Associations of pentraxin 3 with cardiovascular disease and all-cause death. Arteriosclerosis, Thrombosis, and Vascular Biology 200929 594-599. (doi:10.1161/ATVBAHA.108.178947)

9 Dubin R, Li Y, Ix JH, Shlipak MG, Whooley M \& Peralta CA. Associations of pentraxin-3 with cardiovascular events, incident heart failure, and mortality among persons with coronary heart disease: data from the Heart and Soul Study. American Heart Journal 2012163 274-279. (doi:10.1016/j.ahj.2011.11.007)

10 Ryu WS, Kim CK, Kim BJ, Kim C, Lee SH \& Yoon BW. Pentraxin 3: a novel and independent prognostic marker in ischemic stroke. Atherosclerosis 2012220 581-586. (doi:10.1016/j.atherosclerosis.2011.11.036)

11 Garlanda C, Maina V, Cotena A \& Moalli F. The soluble pattern recognition receptor pentraxin-3 in innate immunity, inflammation and fertility. Journal of Reproductive Immunology 200983 128-133. (doi:10.1016/j.jri.2009.05.006)

12 Inforzato A, Jaillon S, Moalli F, Barbati E, Bonavita E, Bottazzi B, Mantovani A \& Garlanda C. The long pentraxin PTX3 at the crossroads between innate immunity and tissue remodelling. Tissue Antigens 2011 77 271-282. (doi:10.1111/j.1399-0039.2011.01645.x)

13 Salustri A, Garlanda C, Hirsch E, De Acetis M, Maccagno A, Bottazzi B, Doni A, Bastone A, Mantovani G, Beck-Pecoz P et al. PTX3 plays a key role in the organization of the cumulus oophorus extracellular matrix and in vivo fertilization. Development 2004131 1577-1586. (doi:10.1242/dev.01056)

14 Scarchilli L, Camaioni A, Bottazzi B, Negri V, Doni A, Deban L, Bastone A, Salvatori G, Mantovani A, Siracusa G et al. PTX3 interacts with inter- $\alpha$-trypsin inhibitor: implications for hyaluronan organization and cumulus oophurus expansion. Journal of Biological Chemistry 2007282 30161-30170. (doi:10.1074/jbc.M703738200)

15 Aydogdu A, Tasci I, Tapan S, Basaran Y, Aydogan U, Meric C, Sonmez A, Aydogdu S, Akbulut H, Taslipinar A et al. High plasma level of long pentraxin 3 is associated with insulin resistance in women with polycystic ovary syndrome. Gynecological Endocrinology 201228 722-725. (doi:10.3109/09513590.2011.652719)
16 The Rotterdam ESHRE/ASRM-sponsored PCOS consensus workshop group. Revised 2003 consensus on diagnostic criteria and long term health risks related to polycystic ovary syndrome (PCOS). Fertility and Sterility 200481 19-25.

17 Moghetti P, Tosi F, Bonin C, Di Sarra D, Fiers T, Kaufman JM, Giagulli V Zambotti F, Dall'Alda M, Spiazzi G, Zanolin ME et al. Divergences in insulin resistance between the different phenotypes of the polycystic ovary syndrome. Journal of Clinical Endocrinology and Metabolism 2013 98 E628-E637. (doi:10.1210/jc.2012-3908)

18 Azziz R, Carmina E, Dewailly D, Diamanti-Kandarakis E, EscobarMorreale HF \& Futterweit W. The Androgen Excess and PCOS Society criteria for the polycystic ovary syndrome: the complete task force report. Fertility and Sterility 200991 456-488. (doi:10.1016/j.fertnstert. 2008.06.035)

19 Hatch R, Rosenfield RL, Kim MH \& Tredway D. Hirsutism: implications, etiology, and management. American Journal of Obstetrics and Gynecology $1981140815-830$.

20 Matthews DR, Hosker JP, Rudenski AS, Maylor BA, Treacher DF \& Turner RC. Homeostasis model assessment: insulin resistance and $\beta$-cell function from fasting plasma glucose and insulin concentrations in man. Diabetologia 198528 412-419. (doi:10.1007/BF00280883)

21 DeFronzo RA, Tobin JD \& Andres R. Glucose clamp technique: a method for quantifying insulin secretion and resistance. American Journal of Physiology 1979237 E214-E223.

22 Tosi F, Dorizzi R, Castello R, Maffeis C, Spiazzi G, Zoppini F, Muggeo M $\&$ Moghetti P. Body fat and insulin resistance independently predict serum C-reactive protein in hyperandrogenic women with polycystic ovary syndrome. European Journal of Endocrinology 2009161 737-745. (doi:10.1530/EJE-09-0379)

23 Gray DS, Bray GA, Gemayel N \& Kaplan K. Effect of obesity on bioelectrical impendance. American Journal of Clinical Nutrition 198950 255-260.

24 Vermeulen A, Verdonck L \& Kaufman JM. A critical evaluation of simple methods for the estimation of free testosterone in serum. Journal of Clinical Endocrinology and Metabolism 199984 3666-3672. (doi:10.1210/jc.84.10.3666)

25 Friedewald WT, Levy RI \& Fredrickson DS. Estimation of the concentration of low density lipoprotein cholesterol in plasma, without use of preparative ultracentrifuge. Clinical Chemistry 197218 499-502.

26 Doni A, Michela M, Bottazzi B, Peri G, Valentino S, Polentarutti N, Garlanda C \& Mantovani A. Regulation of PTX3, a key component of humoral innate immunity in human dendritic cells. Stimulation by IL-10 and inhibition by IFN- $\gamma$. Journal of Leukocyte Biology 200679 797-802. (doi:10.1189/jlb.0905493)

27 Fazzini F, Peri G, Doni A, Dell'Antonio G, Dal Cin E, Bozzolo E, D'Auria F, Praderio L, Ciboddo G, Sabbadini MG et al. PTX3 in small-vessel vasculitides: an independent indicator of disease activity produced at sites of inflammation. Arthritis and Rheumatism 200144 2841-2850. (doi:10.1002/1529-0131(200112)44:12<2841::AIDART472>3.0.CO;2-6)

28 Yoneda M, Uchiyama T, Kato S, Endo H, Fujita K, Yoneda K, Mawatari H, Iida H, Takahashi H, Kirikoshi H et al. Plasma pentraxin 3 is a novel marker for nonalcoholic steatohepatitis (NASH). BMC Gastroenterology 20088 53. (doi:10.1186/1471-230X-8-53)

29 Lim SS, Norman RJ, Davies MJ \& Moran LJ. The effect of obesity on polycystic ovary syndrome: a systematic review and meta-analysis. Obesity Reviews 2012 1495-109. (doi:10.1111/j.1467-789X.2012.01053.x)

30 Piltonen T, Puurunen J, Hedberg P, Ruokonen A, Mutt SJ, Herzig KH, Nissinen A, Morin-Papunen L \& Tapanainen JS. Oral, transdermal and vaginal combined contraceptives induce an increase in markers of chronic inflammation and impair insulin sensitivity in young healthy normal-weight women: a randomized study. Human Reproduction 2012 27 3046-3056. (doi:10.1093/humrep/des225)

31 Gonzalez F, Sia CL, Stanczyk FZ, Blair HE \& Krupa ME. Hyperandrogenism exerts an anti-inflammatory effect in obese women with 
polycystic ovary syndrome. Endocrine 201242 726-735. (doi:10.1007/ s12020-012-9728-6)

32 Malkin CJ, Pugh PJ, Jones RD, Jones TH \& Channer KS. Testosterone as a protective factor against atherosclerosis-immunomodulation and influence upon plaque development and stability. Journal of Endocrinology 2003178 373-380. (doi:10.1677/joe.0.1780373)

33 Pergola C, Rogge A, Dodt G, Northoff H, Weinigel C, Barz D, Rådmark O, Sautebin L \& Werz O. Testosterone suppresses phospholipase D, causing sex differences in leukotriene biosynthesis in human monocytes. FASEB Journal 201125 3377-3387. (doi:10.1096/fj.11-182758)

34 Yamasaki K, Kurimura M, Kasai T, Sagara M, Kodama T \& Inoue K. Determination of physiological plasma pentraxin 3 (PTX3) levels in healthy populations. Clinical Chemistry and Laboratory Medicine 200947 471-477. (doi:10.1515/CCLM.2009.110)

35 Legro RS. Polycystic ovary syndrome and cardiovascular disease: a premature association? Endocrine Reviews 200324 302-312. (doi:10.1210/er.2003-0004)

36 Alexandersen P, Haarbo J, Byrjalsen I, Lawaetz H \& Christiansen C. Natural androgens inhibit male atherosclerosis: a study in castrated, cholesterol-fed rabbits. Circulation Research 199984 813-819. (doi:10.1161/01.RES.84.7.813)

37 Hanke H, Lenz C, Hess B, Spindler KD \& Weidemann W. Effect of testosterone on plaque development and androgen receptor expression in the arterial vessel wall. Circulation 2001103 1382-1385. (doi:10.1161/01.CIR.103.10.1382)

38 Bernini GP, Sgrò M, Moretti A, Argenio GF, Barlascini CO, Cristofani R $\&$ Salvetti A. Endogenous androgens and carotid intimal-medial thickness in women. Journal of Clinical Endocrinology and Metabolism 199984 2008-2012. (doi:10.1210/jc.84.6.2008)

39 Bernini GP, Moretti A, Sgrò M, Argenio GF, Barlascini CO, Cristofani R $\&$ Salvetti A. Influence of endogenous androgens on carotid wall in postmenopausal women. Menopause 20011 43-50. (doi:10.1097/ 00042192-200101000-00008)

40 Norata GD, Garlanda C \& Catapano AL. The long pentraxin PTX3: a modulator of the immunoinflammatory response in atherosclerosis and cardiovascular diseases. Trends in Cardiovascular Medicine 201020 35-40. (doi:10.1016/j.tcm.2010.03.005)

41 Yudkin JS, Stehouwer CD, Emeis JJ \& Coppack SW. C- reactive protein in healthy subjects: associations with obesity, insulin resistance, and endothelial dysfunction: a potential role for cytokines originating from adipose tissue? Arteriosclerosis, Thrombosis, and Vascular Biology 199919 972-978. (doi:10.1161/01.ATV.19.4.972)

42 Varani S, Elvin JA, Yan C, DeMayo J, DeMayo FJ, Horton HF, Byrne MC \& Matzuk MM. Knockout of pentraxin 3, a downstream target of growth differentiation factor-9, causes female subfertility. Molecular Endocrinology 200216 1154-1167. (doi:10.1210/me.16.6.1154)

43 Yang J-L, Zhang C-P, Li L, Huang L, Ji S-Y, Lu C-L, Fan C-H, Cai H, Ren Y, $\mathrm{Hu} \mathrm{Z}-\mathrm{Y}$ et al. Testosterone induces redistribution of forkhead box-3a and down-regulation of growth and differentiation factor 9 messenger ribonucleic acid expression at early stage of mouse folliculogenesis. Endocrinology 2010151 774-782. (doi:10.1210/ en.2009-0751)

44 Zhao SY, Qiao J, Chen YJ, Liu P, Li J \& Yan J. Expression of growth differentiation factor-9 and bone morphogenetic protein-15 in oocytes and cumulus granulosa cells of patients with polycystic ovary syndrome. Fertility and Sterility 201094 261-267. (doi:10.1016/ j.fertnstert.2009.03.014)

45 Wei LN, Liang XY, Fang C \& Zhang MF. Abnormal expression of growth differentiation factor 9 and bone morphogenetic protein 15 in stimulated oocytes during maturation from women with polycystic ovary syndrome. Fertility and Sterility 201196 464-468. (doi:10.1016/ j.fertnstert.2011.05.036)

Received 18 September 2013

Revised version received 13 November 2013

Accepted 17 December 2013 